\title{
Smart switchboards positioning in microgrids
}

\author{
A. Vianna ${ }^{1}$, R. Souza ${ }^{1}$, R. Calili ${ }^{2}$ \\ ${ }^{1}$ Electrical Engineering Departament \\ Pontifical Catholic University - PUC \\ 22451-900 Rio de Janeiro, RJ, (Brazil) \\ Phone/Fax number: 005521 35271202, e-mail: ajbvianna@gmail.com, reinaldo@ele.puc-rio.br \\ ${ }^{2}$ Postgraduate Program in Metrology \\ Pontifical Catholic University - PUC \\ 22451-900 Rio de Janeiro, RJ, (Brazil)
}

Phone/Fax number: 005521 35271001, e-mail: rcalili@esp.puc-rio.br

\begin{abstract}
: this work develops an approach to smart switchboards allocation in industrial plants and microgrids aimed at optimizing the cost of electric cables. A case study is presented where the proposed methodology is applied and the results are compared with the actual data extracted from a conventional design to the same plant without using any smart technique for allocation of the switchboard. The cost savings are significant and extend to $\mathrm{CO}_{2}$ emissions.
\end{abstract}

Key Words: smart grids, smart allocation of switchboards, optimization of electrical cable costs, genetic algorithms.

\section{Interest of Work}

In low voltage industrial plants and microgrids a significant portion of the cost needed for its construction is concentrated in electrical installations. In this context, the power lines are the most important item in economic terms and few initiatives aimed at their reduction have been noted. Despite the limitations imposed by current regulations and by the users of these plants, there are steps that can lead to reducing the cost of electric cables, among them the intelligent allocation of switchboards at low voltage.

\section{Introduction}

In medium and large industrial and commercial facilities the cost of electrical cables is significant. Depending on the geographical characteristics of the place and nature of the charges to be met, the cost of the cables may represent between $10 \%$ and $30 \%$ of the total work setting up an item of extreme importance during the design stages of these facilities.

The positioning constraints of the wires that are too severe for high-voltage systems are not repeated in low-voltage circuits allowing its placement varies with much more freedom along the area of the facility to search for better placement.

The infrastructure to driving and protection of electrical cables varies slightly depending on the variation of the square section of the cables and even then, if any, this change has very limited economic impact. This means that changes in the dimensioning of the cables of an installation does not cause significant increases in the cost of the other items of the work.

Given the above it is easy to see that optimize the use of cables in a low voltage installation means a direct reduction in the cost of electrical work without unwanted side effects. Another important aspect that is increasing the importance each day is sustainability to minimize the use of copper and $\mathrm{CO}_{2}$ emissions. For these reasons it is understood that the step of positioning switchboards at electrical design deserves the use of more efficient than current techniques in order to minimize the use of cables.

To be able to have completely set up the problem of minimizing cable use on a low voltage installation some aspects should be considered, such as:

- Positioning of the switchboard;

- Positioning of the substation or main switchboard for low voltage;

- Positioning of loads and design of circuits;

- Constraints imposed by the installation, by the regulatory rules and by the user.

The positioning of switchboards, substation and charges to be met along the area of a facility is a definition of the basic design that traditionally considers criteria such as: ease of installation, cost, access, security, spatial organization, among others [2]. As noted, costs are also considered, but not the thorough way it should be, after all the designer will be dealing with hundreds of electrical circuits and thousands of positioning possibilities which would make impossible the task without the support of other more modern techniques based on computing.

Another component of this problem are the criteria used in electrical standards as well as those who have become customary between designers and invariably oversizing electrical circuits especially those circuits whose diversity of charges is greater, for which the defined use of factors often add a substantial safety margin in electric cables which makes the problem even more delicate and relevant. 
The last aspect is the positioning limitations of switchboards and substation that the design must meet, some of them physical, such as walls, partitions, doors, windows, columns, beams, rails, proximity to other facilities, etc. Others set by users, such as restricted areas, concentration of loads in certain parts, escape routes, visual comfort, etc. Often these restrictions are so stringent that greatly limit the placement options for switchboards requiring a much larger investment [2].

The analysis of these three aspects is very difficult when applied to real situations where a medium-sized plant easily reaches the order of hundreds of electrical circuits while the area is on the order of thousands of square meters, indicating a great number of positioning possibilities not allowing the simple exhaustive search of the solution.

This paper only addressed the positioning optimization of electrical switchboards and its effects on the installation cost. Does not change at all the aspects related to cable dimensioning, following fully the guidelines of Brazilian standards, NBR5410. With regard to installation restrictions were analyzed some, but without exhausting the many restriction possibilities of this kind of problem.

\section{Objectives}

The main objective of this work is to achieve the most intelligent positioning for distribution boards in an industrial plant knowing where the loads to be fed are positioned to minimize the cost of electric cables. Are analyzed various aspects that interfere in this process such as:

- Restrictions on the placement of switchboards throughout the plant;

- Regulatory and installation restrictions;

- Composition of loads of electrical circuits;

- Copper price variation in the market.

Then makes a comparison of the cost of wiring from an actual industrial plant carried out in the traditional way, with the same facility performed by the intelligent allocation or positioning of the switchboards at which point it is noted that the potential of reduction for the use of intelligent positioning can be quite significant.

The secondary objective of this study is to estimate the reduction in $\mathrm{CO}_{2}$ emissions resulting from the intelligent allocation of the switchboards.

\section{Cost reduction by the switchboards positioning}

The cost "Switchboard x Substation" is calculated by the following equation:

$$
C_{s u b-Q D}=\sum_{i=1}^{n}\left|\left(d x_{i}-d x_{s u b}\right)+\left(d y_{i}-d y_{s u b}\right)\right| \cdot P_{s u b-Q D i}
$$

Where:

$$
\begin{array}{ll}
C_{s u b-Q D} & \text { Is the cost of cable between the switchboard i and } \\
\text { substation in Brazilian Real; }
\end{array}
$$

$$
\begin{array}{ll}
d x_{i}-d x_{\text {sub }} & \text { Is the distance on the } \mathrm{x} \text { axis between the } \\
\text { substation and the switchboard } \mathrm{i} \text { in meters; } \\
d y_{i}-d y_{s u b} \quad \begin{array}{l}
\text { Is the distance in the } \mathrm{y} \text { axis between the substation } \\
\text { and the switchboard } \mathrm{i} \text { in meters; }
\end{array} \\
P_{\text {sub-QDi }} & \text { Is the unit price of the cable that feed the }
\end{array}
$$

The cost "Switchboard x Load" is calculated by the following equation:

$$
C_{l-Q D}=\sum_{i=1}^{n} \sum_{j=1}^{m}\left|\left(d x_{i}-d x_{l}\right)+\left(d y_{i}-d y_{l}\right)\right| \cdot P_{l j-Q D i}
$$

where:

$$
\begin{aligned}
& C_{l-Q D} \quad \text { Is the cost of cable between the switchboards } i \text { and } \\
& d x_{i}-d x_{l} \quad \text { Is the distance in the } \mathrm{x} \text {-axis between load } \mathrm{j} \text { and } \\
& d y_{i}-d y_{l} \quad \text { Is the distance in the } \mathrm{y} \text {-axis between load } \mathrm{j} \text { and } \\
& \text { switchboard i, in meters; } \\
& P_{l j-Q D i} \quad \text { Is the unit price of the sized cable to feed each } \\
& \text { load from the switchboard } i \text {, in Brazilian } \\
& \text { Real/meter; } \\
& n \quad \text { Is the total number of switchboards; } \\
& m \quad \text { Is the number of loads on each switchboard. }
\end{aligned}
$$

From these equations we reach the total cost defined by the placement of switchboards, substation and loads, as:

$$
C_{\text {total }}=C_{\text {sub-QD }}+C_{l-Q D}
$$

We can summarize the problem defined by the above equations as follows where we have:

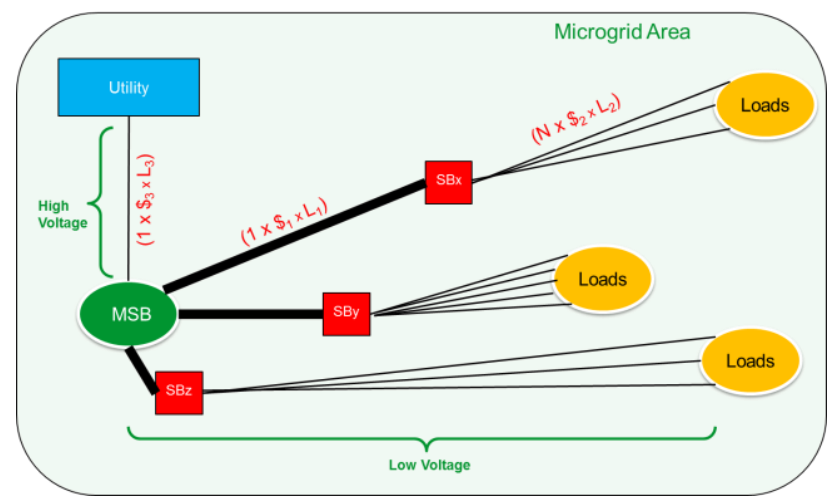

Figure 1 - Cost of electric cables depending on the position of switchboards

- Hard conditions:
○ The dimensions of the plant;
- The position of the loads;
- The position of the substation;
- The price of electric cables.
○ The composition of switchboards;
- The number of switchboards;

- Variable conditions:
- The switchboard position; 


\section{Cost Reduction by Composition and Quantity of Switchboards}

Note that the composition and quantity of switchboards were considered fixed conditions, but changing them is a real option, without major impediments or repercussions of electrical point of view.

Changing the composition of load feeders of the switchboard is possible to obtain a more homogeneous set of circuits, where all of the same type and therefore where a positioning decision will have a beneficial effect for all load feeders and not good for some, but not as good for others. A worst case would be the case where positioning decision results good for some load feeders and bad for the others leading to a neutralizing effect and an erroneous finding that the optimization process had reached its limit.

The best group or set is the one that allows the switchboard has a marked feature:

- Type "load": more economical close to the load;

- Type "source": more economical close to the source.

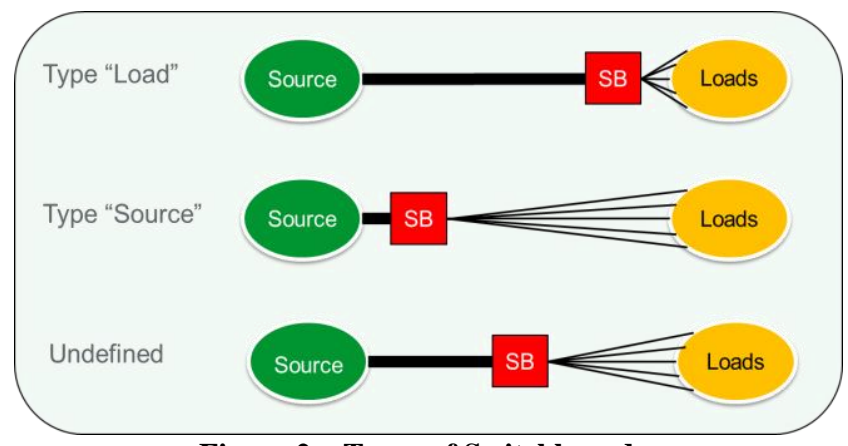

Figure 2 - Types of Switchboards

However, exploring all its possibilities means to greatly expand the number of cases to be studied.

The universe of possibilities of various switchboards composition options is the simple combination of circuit number set for the switchboard by existing circuits in the project, which is defined by the following combination:

$$
\left(\begin{array}{l}
t \\
k
\end{array}\right)=\frac{t !}{k ! \cdot(t-k) !}
$$

Where:

$$
\begin{array}{ll}
t & \text { is the total number of circuits in the project; } \\
k & \text { is the number of circuits provided to the } \\
\text { switchboard. }
\end{array}
$$

Quantifying this number to a facility with 10 switchboards with 8 circuits each to meet the needs of a hypothetical project of 80 circuits, one reaches the following number of possible compositions for switchboards:

$$
\left(\begin{array}{c}
80 \\
8
\end{array}\right)=\frac{80 !}{8 ! \cdot(80-8) !}=2,9 \cdot 10^{10}
$$

Considering also that the number of circuits provided in each switchboard can range from a minimum of 2 circuits to a maximum of 80 circuits, it has:

$$
\sum_{k=2}^{80}\left(\begin{array}{c}
80 \\
k
\end{array}\right)=\sum_{k=2}^{80} \frac{80 !}{k ! \cdot(80-k) !}
$$

This number would be very high and prevents any mathematical model even using computational tools.

As a result, it was decided to keep these fixed conditions, however it is assumed that manual variations on the composition of switchboards can be performed during the process of mathematical simulation in order to seek to strengthen the feature ("load" or "source") of the switchboards which does not have a well-defined behavior.

\section{6. $\mathrm{CO}_{2}$ emissions}

Environmental losses associated with a particular electrical installation can be quantified by the $\mathrm{CO}_{2}$ emissions associated with the use of electrical cables in this facility, which is also linked the amount of cables used it [1].

Throughout the life cycle of electrical wire and cable, the most significant $\mathrm{CO}_{2}$ emissions are produced when drivers transporting electrical energy, being relatively small in the manufacture and disposal of these products phase. These $\mathrm{CO}_{2}$ emissions result from the extra energy generation needed to compensate for the Joule losses in the conduction of electrical current through the circuit [1], [4]. From this account, the annual avoided emissions of $\mathrm{CO}_{2}$ can be calculated from the following equation, applied to each circuit design [4].

$$
Z_{e v}=Z_{0}-Z_{1}=N_{p} \cdot R \cdot 10^{-3} \cdot i_{\text {nom }}^{2} \cdot\left(L_{1}-L_{0}\right) \cdot \Delta T \cdot k
$$

Where:

$$
\begin{array}{ll}
Z_{e v} & \begin{array}{l}
\text { Is the annual emission of } \mathrm{CO}_{2} \text { avoided in } \\
\left(\mathrm{kg}-\mathrm{CO}_{2}\right) ;
\end{array} \\
Z_{0} & \begin{array}{l}
\text { Is the annual } \mathrm{CO}_{2} \text { emission before the smart } \\
\text { allocation in }\left(\mathrm{kg}-\mathrm{CO}_{2}\right) ;
\end{array} \\
Z_{1} & \begin{array}{l}
\text { Is the annual } \mathrm{CO}_{2} \text { emission after the smart } \\
\text { allocation in }\left(\mathrm{kg}-\mathrm{CO}_{2}\right) ;
\end{array} \\
\mathrm{Np} & \text { Is the number of phase conductors; } \\
R & \begin{array}{l}
\text { Is the electrical resistance of the conductive } \\
\text { material }(\Omega . \mathrm{km}) ;
\end{array} \\
L_{1} & \begin{array}{l}
\text { Is the length of the conductive material of } \\
\text { the circuit after the smart allocation of }(\mathrm{km}) ;
\end{array} \\
L_{0} & \begin{array}{l}
\text { Is the length of the conductive material of } \\
\text { the circuit before the smart allocation of } \\
\text { (km); }
\end{array} \\
k T & \begin{array}{l}
\text { Is the circuit operation time interval }(\mathrm{h} / \mathrm{year}) ; \\
\text { Is the emission of } \mathrm{CO}_{2} \text { when generating } \\
\text { electricity by unit in }\left(\mathrm{kg}-\mathrm{CO}_{2} / \mathrm{kWh}\right) ;
\end{array}
\end{array}
$$

Applying this equation to all the circuits of a facility one has an estimate of $\mathrm{CO}_{2}$ emissions avoided due to the intelligent allocation of the switchboards. It is emphasized 
again that adopting this strategy, emissions from cable manufacturing and disposal cycles are not considered since for this should be made a full analysis of the production chain of copper cables.

\section{Optimization Technique}

The proposed solution to this problem was to develop an optimization program capable of testing thousands of relative positioning combinations "Switchboards x Loads" and "Switchboards x Substation" evaluating in each case the total cost of the solution.

The use of genetic algorithms as optimization technique initially was due to great similarity between the various applications of positioning in the literature and the positioning of the switchboard [3]. Later, after detailed study other aspects of the problem, the decision was ratified that this artificial intelligence technique was suitable for the resolution of this problem [5]. The following figure summarizes this scenario.

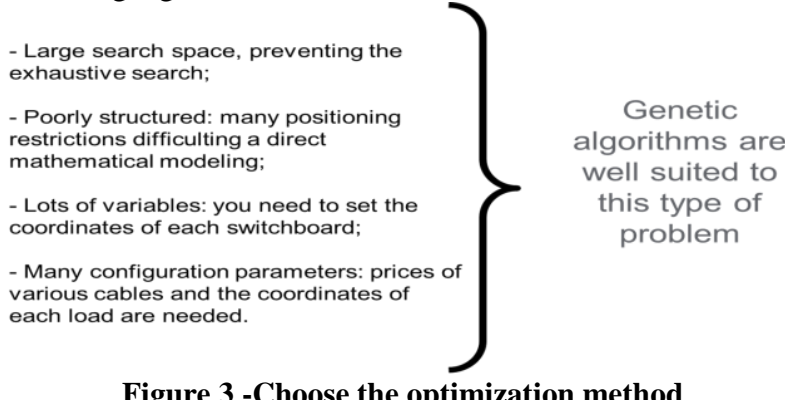

Figure 3 -Choose the optimization method

Well configured genetic algorithms can test the various regions of the search space without losing sight of the goal of optimization and also allow the inclusion of restrictions on the model that reflect real difficulties that the project has to overcome [3],[5]. These were the main reasons that led to the adoption of this optimization technique in solving the problem.

The modeling of the genetic algorithm was as follows:

a) Representation: real representation with 2 decimal places to display the positions of the various elements;

b) Chromosome: set of positions of "n" switchboards as well as the position of the substation;

c) Evaluation function: the function that evaluates the suitability of the proposed solution by the genetic algorithm is equation (1);

d) Restrictions:

- Adopted a configurable restriction of maximum distance from the switchboard to walls that determine the perimeter of the area;

- Is considered that the substation should be positioned in one of the outer walls assuming $y=0$ and $\mathrm{x}$ variable;

- It merely positioning of switchboards the inner area of the installation.

e) Crossover: was used uniform crossover at a rate of 0.8 . f) Mutation: the mutation operator was set to a high rate of 0.25 aiming to force the algorithm to test solutions in various areas of the search space.

The implementation of the genetic algorithm was held at Evolver 6.2.1 application environment in a trial version available from the manufacturer. This application is part of a set of add-ins called Decision Tools Suite (DTS) developed by Palisade Corporation for use with Microsoft Excel 2003 and later.

Besides this, in the same Excel environment, was developed an animated graphic interface using a scatter graph was prepared to show, in real time, the tested positions of the switchboard and substation along the plant online with the optimization process progresses. In the following figure shows the graphical interface showing the area of the plant with the positioning of loads (fixed), the switchboards and substation (mobile).

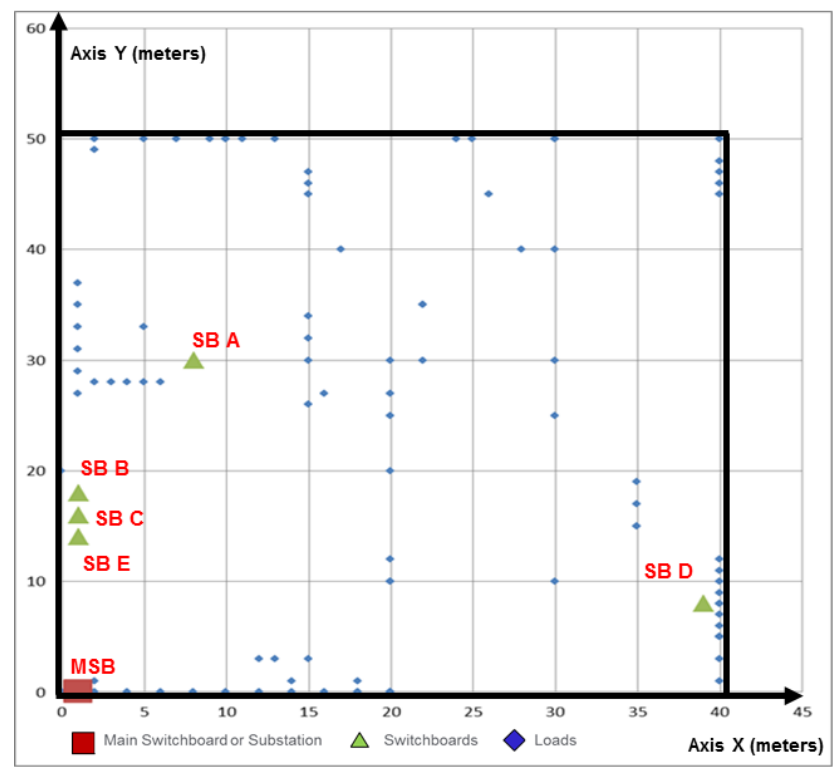

Figure 4 - Graphical Interface

\section{Methodology for Smart Allocation}

Can establish a methodology for the smart allocation of switchboards at low voltage that is easily applied in the electrical environment and bring effective results with respect to cost optimization. This methodology was designed for the use of genetic algorithms by Evolver 6.2.1 application, below are listed the steps that define the method:

\section{Assumptions}

a) The charges have a fixed position;

b) The prices of electrical cables are fixed;

c) The cost is only due to the cost of electric cables;

d) Setting by basic design method the original reference positioning of the switchboards and substation whose cost will be compared to the cost result of positioning defined by the smart allocation; 
Step 1: Data collection

1) Set the overall dimensions of the area over which the loads are distributed, the switchboards and the substation or main switchboard;

2) Set the restrictions on use of the area defined in item 1, with the end-user setting the spaces where it allows the installation of switchboards and substation; 3) Set the electrical characteristics of the loads as well as its positioning within the study area;

4) Quote the local market electrical cables, defining its cost per linear meter;

\section{Step 2: Electric Project}

5) Set the restrictions on use of the area defined in item 2, following local standards (e.g. in Brazil: NBR5410 standard), establishing viable space for installing switchboards and substation;

6) Define how many switchboards will be used and which circuits comprise each of them;

7) Specify the cables required to meet the feeders loads and general feeders of the switchboards according to the standard criteria;

\section{Step 3: Mathematical Model}

8) Definition of genetic algorithm evaluation function based on the equation 1, tailored to the application's data entry Evolver 6.2.1;

9) Mathematical definition of positioning constraints defined by item 2 and 5 of this methodology adapting them to the application's data entry Evolver 6.2.1;

10) Definition of typical configurations to be tested by varying the number of trials and population size in order to get the best performance of the genetic algorithm;

11) Setting the other parameters of the genetic algorithm as the application configuration windows Evolver 6.2.1;

12) Setup of application constraints solver for the generation of random initial values that meet defined constraints, according to the specific application configuration window;

13) Simulate a number equal to or greater than 20 trials for each of typical configurations defined in item 10 by calculating the mean value and the standard deviation of the results obtained for each typical configuration;

\section{Step 4: Results and adjust}

14) Assess whether the results are appropriate to the reality in terms of positioning. If necessary refine the defined constraints;

15) Evaluation of the cost reduction compared to the original position defined by " $\mathrm{d}$ " premise;

16) Analysis of sensitivity by variation in the circuit composition of the switchboards which are contributing more significantly to the total cost and the feasibility of subdividing it into two or more new switchboards and group them into other existing switchboards.

\section{Case Study}

The actual data used were obtained from a mechanic industry operating in the aerospace and defense sector, established in the metropolitan area of the city of Rio de Janeiro who recently started a new assembly line at its plant. Data rightly belong to the basic electrical design of this new assembly line that today is already in operation. It is an assembly hangar with a rectangular floor $2000 \mathrm{~m} 2$, serving 97 electric low-voltage circuits (220V and 440V), through 5 switchboards powered by a single unit substation. Figure 4 presents the spatial arrangement proposed by the basic design for this assembly hangar whose data formed the basis for the comparison of results. The distribution boards should be close to the walls that surrounded the perimeter of the plant so that there was no prejudice to the central area for equipment assembly. A maximum distance of 2 meters of each wall was considered.

The substation (MSB) feeding the plant could vary its position along only one of the walls since the high voltage feeders could not be relocated freely by the industry for safety reasons. It adopted the $\mathrm{X}$ axis as allowed for the variation of MSB position.

\section{Results}

Were made 4 experiments, each with 20 samples and optimization of them were mixed population size from 100 to 500 subjects and the number of attempts from 1000 to 2000. The initial values used in optimizations were generated randomly by the Evolver constraints solver so that it is random values, but at the same time heeding the constraints defined in the model. The following tables summarize the results.

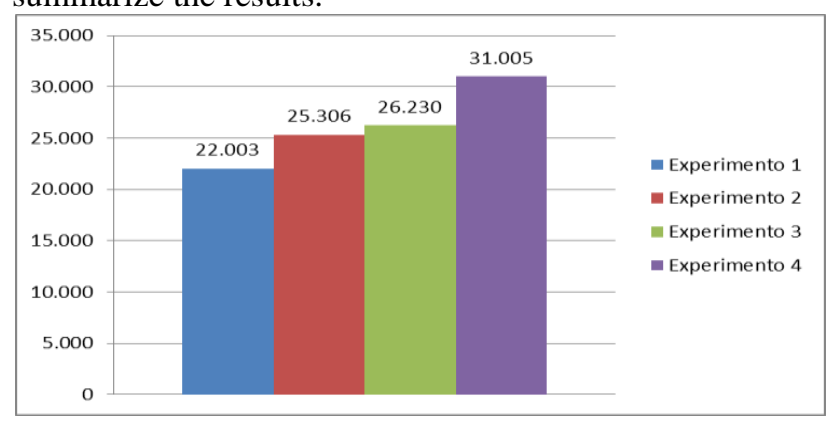

Figure 5 - Average Cost

In the positioning defined by basic design without the application of smart allocation methodology, the total cost with electric cables was $\mathrm{R} \$ 36.704,00$. The table 1 shows the total cost of the electrical cables allocating the switchboards in positions defined in the basic design through the traditional methodology, and the positions defined by the best sample among the 80 that used the methodology of smart allocation method. The coordinates of the achieved switchboards at the end of the table shows is calculated by the percentage of reduction compared to the basic design method that the best sample reached. 
Table 1 - Comparative analysis of the cost of the cables

\begin{tabular}{|c|c|c|c|c|c|c|}
\hline \multirow{2}{*}{ Switchboard } & \multicolumn{3}{|c|}{ Basic Design Method } & \multicolumn{3}{c|}{$\begin{array}{c}\text { Smart Allocation Method } \\
\text { Sample 6 }\end{array}$} \\
\cline { 2 - 7 } & Axis X (m) & Axis Y (m) & \$ & Axis X (m) & Axis Y (m) & $\$$ \\
\hline SB A & 8 & 30 & 16.136 & 17,0438696 & 2 & 15.047 \\
\hline SB B & 1 & 18 & 1.412 & 17,139414 & 2 & 616 \\
\hline SB C & 1 & 16 & 7.513 & 16,9232495 & 0,2439904 & 1.690 \\
\hline SB D & 39 & 8 & 1.164 & 17,2988289 & 2 & 587 \\
\hline SB E & 1 & 14 & 10.479 & 17,0787023 & 0,8873054 & 1.913 \\
\hline Substation & 1 & 2 & - & 17,0472 & 0 & - \\
\hline \$ Total & \multicolumn{3}{|c|}{$\mathbf{3 6 . 7 0 4}$} & \multicolumn{3}{|c|}{$\mathbf{1 9 . 8 5 4}$} \\
\hline (\%) & $\mathbf{1 0 0} \%$ & \multicolumn{5}{c|}{$\mathbf{5 4} \%$} \\
\hline
\end{tabular}

The spatial positioning of the best sample is shown in the following figure.

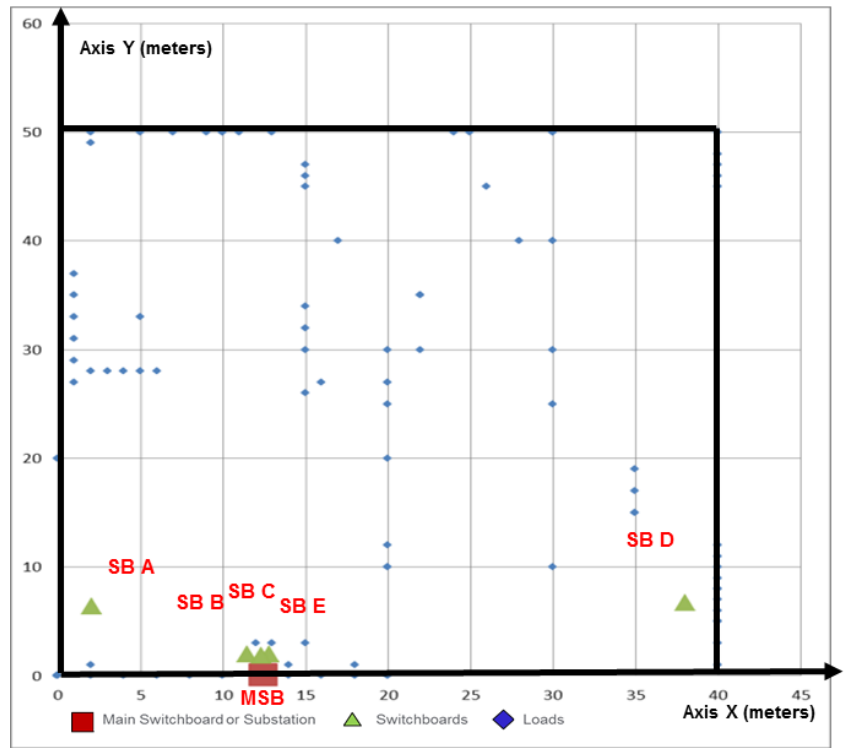

Figure 6 - Spatial positioning of better sample

The table 2 shows the annual $\mathrm{CO}_{2}$ emissions avoided for each defined position: basic design method and the best sample using the methodology of smart allocation. At the end of the table is calculated the percentage of $\mathrm{CO}_{2}$ emissions compared to the basic design method of the best sample reached using the assumption that each circuit operates 100 hours per month.

Table 2 - Comparative analysis of $\mathrm{CO}_{2}$ emissions

\begin{tabular}{|c|c|c|c|c|c|c|}
\hline \multirow{3}{*}{ Switchboard } & \multirow{2}{*}{\multicolumn{3}{|c|}{ Basic Design Method }} & \multirow{2}{*}{\multicolumn{3}{|c|}{$\begin{array}{c}\text { Smart Allocation Method } \\
\text { Sample } 6\end{array}$}} \\
\hline & & & & & & \\
\hline & Axis $X(m)$ & Axis $Y(m)$ & \begin{tabular}{|c|} 
Emissions \\
$\left(\mathrm{kg}-\mathrm{CO}_{2} /\right.$ year)
\end{tabular} & Axis X (m) & Axis $Y(m)$ & $\begin{array}{c}\text { Emissions } \\
\text { (kg- }-\mathrm{CO}_{2} / \text { year) }\end{array}$ \\
\hline SB A & 8,0 & 30,0 & 360 & 17,0 & 2,0 & 326 \\
\hline SB B & 1,0 & 18,0 & 70 & 17,1 & 2,0 & 24 \\
\hline SB C & 1,0 & 16,0 & 584 & 16,9 & 0,2 & 158 \\
\hline SB D & 39,0 & 8,0 & 123 & 17,3 & 2,0 & 22 \\
\hline SBE & 1,0 & 14,0 & 517 & 17,1 & 0,9 & 78 \\
\hline Substation & 1,0 & 2,0 & - & 17,0 & 0,0 & - \\
\hline $\begin{array}{c}\text { Total Loss } \\
\text { (kg-CO } / \text { year) }\end{array}$ & \multicolumn{3}{|c|}{1.653} & \multicolumn{3}{|c|}{608} \\
\hline$(\%)$ & \multicolumn{3}{|c|}{$100 \%$} & \multicolumn{3}{|c|}{$36,8 \%$} \\
\hline
\end{tabular}

When comparing the results of smart allocation method with the values achieved by the basic design method comes to the following numbers:

- Basic Design Method = R\$ 36.704,00

- Smart Allocation Method = R\$ 19.854,00

- Difference $=\mathrm{R} \$ 16.850,00$ or $45,9 \%$
Whereas the cables can cost up to $30 \%$ of the value of a work of this nature, there is a saving on the total value of the work in the order of $13.8 \%$, which shows that the use of an intelligent method for this definition of design is justified.

\section{Conclusions}

Among the conclusions reached after analyzing the results, follow the most relevant:

a) A significant reduction in the cost of electrical cables obtained in the comparative analysis achieved only with the repositioning of the switchboard demonstrates that the use of smart allocation methodology is warranted, and their implementation should be an indispensable part of the electrical design for industries and large installations.

b) The study is very dependent on the cable price list used which in turn varies depending on the country, the region and the global demand for copper indicating that the results are not definitive and may be different with each new study because market conditions may have changed.

c) it can tell that depending on the composition of the load feeders switchboard it will be more economical if installed nearest to the loads or closest to the substation. One can consider adjusting this composition or that grouping, such as fine tuning of the smart allocation of switchboards.

d) Advancing this analysis, it can be concluded that, when the optimal position of the switchboard is not even very near to the substation (source) or very close to the load its composition is not homogeneous; having in the same switchboard, load feeders "load type" and "source type" which balance and thus both not fully enjoy the benefits of smart allocation.

\section{References}

[1] CALILI, R.F., SOUZA, R.C., GALLI, A., ARMSTRONG, M., MARCATO, A.L.M., Estimating the Cost Savings and Avoided $\mathrm{CO} 2$ Emissions in Brazil by Implementing Energy Efficient Policies, Energy Policy, Elsevier Journal, 2013.

[2] VIANNA, A.J.B., Intelligent Application of Switchboards in Low Voltage, Master's thesis, PUC-RJ, 2015.

[3] MEHRIZI-SANI, A., IRAVANI, R., Potencial-Function Based Control of a MicroGrid in Islanded and GridConnected Modes, IEEE Transactions on Power Systems, Vol.25, No 4, 2010.

[4] MORENO, H., Economic and Environmental Dimensioning of Electrical Cables, PROCOBRE, 2010.

[5] PACHECO, M. A. P., Genetic Algorithms: principles and applications, Applied Computational Intelligent Lab, PUCRJ, 1999. 